University of Nebraska - Lincoln

DigitalCommons@University of Nebraska - Lincoln

Nebraska Cooperative Fish \& Wildlife Research Nebraska Cooperative Fish \& Wildlife Research Unit -- Staff Publications

2015

\title{
The Effects of Harvest Regulations on Behaviors of Duck Hunters
}

\author{
Matthew T. Haugen \\ University of Nebraska-Lincoln, mhaug022@gmail.com \\ Larkin A. Powell \\ University of Nebraska-Lincoln, Ipowell3@unl.edu \\ Mark P. Vrtiska \\ Nebraska Game and Parks Commission, mark.vrtiska@nebraska.gov \\ Kevin L. Pope \\ University of Nebraska-Lincoln, kpope2@unl.edu
}

Follow this and additional works at: https://digitalcommons.unl.edu/ncfwrustaff

Part of the Aquaculture and Fisheries Commons, Environmental Indicators and Impact Assessment Commons, Environmental Monitoring Commons, Natural Resource Economics Commons, Natural Resources and Conservation Commons, and the Water Resource Management Commons

Haugen, Matthew T.; Powell, Larkin A.; Vrtiska, Mark P.; and Pope, Kevin L., "The Effects of Harvest Regulations on Behaviors of Duck Hunters" (2015). Nebraska Cooperative Fish \& Wildlife Research Unit -Staff Publications. 148.

https://digitalcommons.unl.edu/ncfwrustaff/148

This Article is brought to you for free and open access by the Nebraska Cooperative Fish \& Wildlife Research Unit at DigitalCommons@University of Nebraska - Lincoln. It has been accepted for inclusion in Nebraska Cooperative Fish \& Wildlife Research Unit -- Staff Publications by an authorized administrator of DigitalCommons@University of Nebraska - Lincoln. 


\title{
The Effects of Harvest Regulations on Behaviors of Duck Hunters
}

\author{
MATTHEW T. HAUGEN, ${ }^{1}$ LARKIN A. POWELL, ${ }^{1}$ \\ MARK P. VRTISKA, ${ }^{2}$ AND KEVIN L. POPE ${ }^{1}$ \\ ${ }^{1}$ School of Natural Resources, University of Nebraska-Lincoln, Lincoln, \\ Nebraska, USA \\ ${ }^{2}$ Nebraska Game and Parks Commission, Lincoln, Nebraska, USA
}

\begin{abstract}
Uncertainty exists as to how duck harvest regulations influence waterfowl hunter behavior. We used the U.S. Fish and Wildlife Service's Parts Collection Survey to examine how harvest regulations affected behaviors of Central Flyway duck hunters. We stratified hunters into ranked groups based on seasonal harvest and identified three periods (1975-1984, 1988-1993, 2002-2011) that represented different harvest regulations (moderate, restrictive, and liberal, respectively; season length and daily bag limits smallest in restrictive seasons and largest in liberal seasons). We examined variability of seven measures of duck hunter behaviors across the periods: days harvesting ducks, daily harvest, hunter mobility, mallard (Anas platyrhynchos) selectivity, gender selectivity, daily female mallard harvest, and timing of harvest. Hunters reported harvesting ducks on more days, at a higher efficiency, and in slightly more counties during liberal seasons relative to restrictive and moderate seasons. We provide evidence to suggest that future regulation change will affect hunter behaviors.
\end{abstract}

Keywords Central Flyway, harvest regulations, hunter characteristics, hunter success, Parts Collection Survey

\section{Introduction}

Waterfowl hunters vary in their experience, skill, dedication, and conservation ethics (Peterle, 1967; Schroeder, Fulton, \& Lawrence, 2006) and hunter behaviors are expected to be influenced by a hunter's individual set of characteristics. Knowledge of the behaviors among hunters (e.g., how much do they move between sites and how selective are they?) is crucial to effective harvest management. But, behaviors must be quantified and it is difficult to study hunters directly in the field without influencing their behavior (Boyd, 1971; Nieman \& Caswell, 1989).

Harvest metrics reported by hunters, however, are likely indicative of waterfowl hunter behaviors. For example, managers currently gather harvest metric data on days harvesting ducks, daily harvest, counties visited to harvest ducks, and timing of harvest that may be linked back to hunter behaviors such as effort, harvest efficiency (e.g., ducks harvested per person per day), and movement. Differences in hunter effort, efficiency, movement, and selectivity may lend insight into differences among hunter characteristics such as skill and experience, persistence and dedication, and conservation concern. For example, if a hunter

Address correspondence to Matthew T. Haugen, Ducks Unlimited Inc., One Waterfowl Way, Memphis, TN 38120, USA. E-mail: mhaug022@gmail.com 
is concerned about mallard (Anas platyrhynchos) population levels, then $\mathrm{s} /$ he may choose to harvest fewer female mallards, which would influence their female mallard selectivity and daily harvest.

Responses of hunter behaviors to regulation change are of management concern. Federal duck harvest regulations are set annually based on waterfowl population statuses and habitat conditions (U.S. Fish and Wildlife Service, 2013). Currently, harvest regulations can be liberal, moderate, or restrictive with liberal seasons providing the longest season lengths and largest daily bags (U.S. Fish and Wildlife Service, 2013). Restrictive seasons offer the shortest season lengths and smallest daily bags (U.S. Fish and Wildlife Service, 2013). Although waterfowl populations and habitat are considered when harvest regulations are set or changed at the federal level, little consideration is given for hunters and their role in duck harvest. Duck harvest regulations can only indirectly affect duck harvest (Johnson \& Case, 2000; Nichols, Runge, Johnson, \& Williams, 2007; U.S. Fish and Wildlife Service, 2013), yet hunter participation and behaviors can directly affect duck harvest. Previous studies have addressed the effect of regulations on duck hunter participation (Enck, Swift, \& Decker, 1993; Miller \& Vaske, 2003; National Flyway Council and Wildlife Management Institute, 2006; Pierce, Ringelman, \& Szymczak, 1996; Ringelman, 1997). These studies, however, are limited by an intuitive disconnect between preferences or satisfactions expressed by hunters and harvest metrics. To meet constituency demands and improve harvest management, managers need to better understand how regulations influence hunter participation and behavior. Knowledge of hunter experience, persistence and dedication, and conservation concern may inform hunter recruitment and retention strategies (Enck et al., 1993; Miller \& Vaske, 2003; Stedman et al., 2004; Van Deelen \& Etter, 2003), addressing the current decline in waterfowl hunter numbers (Vrtiska, Gammonley, Naylor, \& Raedeke, 2013).

Waterfowl managers traditionally have conducted hunter surveys, hosted public meetings, and relied on word of mouth to obtain data on hunter behavior (Johnson, Johnson, Edwards, \& Wheaton, 1993). However, these methods may contain prestige (i.e., bragging; Atwood, 1956) and non-response (Pendleton, 1992) biases. Additionally, traditional methods often rely on hunters to report future intentions or recollect previous events, both of which could be influenced by prestige and memory biases (Atwood, 1956).

In contrast, the U.S. Fish and Wildlife Service's (USFWS) Parts Collection Survey (PCS) is a readily accessible form of data that can be used to examine measures of hunter behaviors. The PCS is used primarily to examine waterfowl harvest (Baldassarre \& Bolen, 2006; Raftovich \& Wilkins, 2013) and has been under-examined with regard to measures of hunter behaviors, even though the PCS contains data keyed to individual hunters that can be interpreted for measures of hunter behaviors. The PCS may be advantageous to traditional survey methods as it may alleviate prestige and non-response biases. Specifically, hunter claims of harvest are substantiated by the parts (i.e., wings) collected from the PCS survey, and hunter participation in the PCS is derived from consenting USFWS Harvest Information Program (HIP) diary data participants (Raftovich \& Wilkins, 2013). Use of the PCS to examine hunter behaviors also has an advantage over traditional methods because data have been collected annually since 1961 (Baldassarre \& Bolen, 2006; Raftovich \& Wilkins, 2013). Thus, the PCS provides an opportunity to examine behavior changes that occur over time or result from regulatory changes. Overall, the PCS can use harvest metrics, or reported behaviors (e.g., days harvesting ducks) to infer actual hunter behaviors.

The HIP diary data also contains data relevant to measures of hunter behaviors. The HIP diary is an annual survey in which hunters voluntarily report daily harvest totals, or seasonal totals of days hunted and ducks harvested. The HIP diary data complements PCS 
data because the HIP data includes hunters who do not harvest ducks on a daily or seasonal basis (i.e., record a "0"), whereas the PCS only includes information from harvest events.

This article used harvest data within the PCS, supplemented with HIP diary data comparisons, to understand how different harvest regulations affected the behaviors of duck hunters. Our objectives were to: (a) characterize measures of behavior for the sample of Central Flyway duck hunters in the PCS; (b) compare measures of hunter behaviors between different regulation sets across groups of stratified hunters; and (c) compare PCS and HIP data behavior results to account the absence of data on hunters who do not harvest ducks seasonally or daily within the PCS.

\section{Methods}

\section{Parts Collection Survey Data and Analyses}

We obtained the PCS data from the USFWS Branch of Harvest Surveys and limited the original PCS database to include only Central Flyway records on duck harvest during regular duck seasons (Kruse, 2013; Kruse, Sharp, Ladd, Moser, \& Bublitz, 2002). We only chose Central Flyway records for consistency in our analyses, as species composition, regulations, and hunting conditions differ between Flyways. Hunters sampled by the PCS were randomly chosen from only successful hunters who participated in the Mail Questionnaire Survey from 1961-2001 (mean response rate for United States $=69 \%, 95 \%$ CI $[68,70]$; USFWS, unpublished data) or HIP diary survey from 2002-2011 (mean response rate for United States $=52 \%, 95 \%$ CI $[49,55]$; USFWS, unpublished data) (Baldassarre \& Bolen, 2006; Martin \& Carney, 1977; Raftovich \& Wilkins, 2013). We removed mergansers (Mergus spp., Lophodytes cucullatus) from the data set because harvest of these species often adheres to separate regulations (Kruse, 2013; U.S. Department of Interior, 2012).

We then divided the PCS database into three periods that represented different harvest regulations or frameworks in the Central Flyway: (a) 2002-2011, with a 6-duck daily bag limit, a 5 mallard/2 female mallard limit, and a 74-day season representing liberal harvest regulations; (b) 1975-1984, with a 5-duck daily bag, a 4 mallard/2 female mallard limit, and a 60-day season representing moderate harvest regulations; and (c) 1988-1993, with a 3-duck daily bag, a 2 mallard/1 female mallard limit, and 39-day season representing restrictive harvest regulations (Kruse, 2013; Kruse et al., 2002). Although daily bag limits and season length were similar from 1997-2011, we did not include 1997-2001 regular duck seasons because allowable start and end dates for duck hunting season were different between 1997-2001 and 2002-2011. Additional season length days for High Plains Management Units (Kruse, 2013; Kruse et al., 2002) were included in our analyses.

We assumed seasonal harvest was a function of hunter skill, experience, or persistence. Thus, we ranked all hunters in the PCS sample in ascending order by seasonal harvest for each period. We then split the ranking into 10 groups of hunters with roughly equivalent sample sizes in each $(\sim 10 \%$ of total sample) (Table 1$)$. We repeated this process for all three periods. The use of deciles for stratification resulted in minor variations in the seasonal harvest among hunter groups in the three periods (Table 1). For example, hunter group $8(\sim 80-89 \%$ in ranked sample $)$ was comprised of hunters who harvested 18-23 ducks seasonally during 2002-2011, 11-14 ducks seasonally during 1975-1984, and 9-11 ducks seasonally during 1988-1993 (Table 1). The use of ranked hunter groups allowed the same relative group of hunters to be compared across regulation sets, because hunter group 10 represented the top-ranked $10 \%$ of hunters (by 
Table 1

Stratification of Central Flyway duck hunters into hunter groups based on seasonal harvest for three harvest regulation periods, derived from U.S. Fish and Wildlife Service Parts Collection Survey data

\begin{tabular}{|c|c|c|c|c|c|c|}
\hline \multirow{3}{*}{$\begin{array}{l}\text { Ranked } \\
\text { hunter group }\end{array}$} & \multicolumn{6}{|c|}{ Harvest regulation period } \\
\hline & \multicolumn{2}{|c|}{$\begin{array}{c}\text { Liberal: } \\
\text { 2002-2011 }\end{array}$} & \multicolumn{2}{|c|}{$\begin{array}{l}\text { Moderate: } \\
\text { 1975-1984 }\end{array}$} & \multicolumn{2}{|c|}{$\begin{array}{l}\text { Restrictive: } \\
\text { 1988-1993 }\end{array}$} \\
\hline & Harvest $^{\mathrm{a}}$ & $\%^{\mathrm{b}}$ & Harvest $\mathrm{t}^{\mathrm{a}}$ & $\%^{\mathrm{b}}$ & Harvest $^{\mathrm{a}}$ & $\%^{\mathrm{b}}$ \\
\hline 1 & $1-2$ & 11.22 & 1 & 11.08 & 1 & 10.93 \\
\hline 2 & $3-4$ & 10.98 & 2 & 10.12 & 2 & 12.01 \\
\hline 3 & $5-6$ & 11.97 & 3 & 9.56 & 3 & 11.07 \\
\hline 4 & $7-8$ & 8.75 & 4 & 7.92 & 4 & 8.28 \\
\hline 5 & $9-10$ & 9.30 & $5-6$ & 12.88 & 5 & 7.43 \\
\hline 6 & $11-13$ & 8.71 & $7-8$ & 9.95 & 6 & 7.73 \\
\hline 7 & $14-17$ & 8.62 & $9-10$ & 10.05 & $7-8$ & 9.55 \\
\hline 8 & $18-23$ & 10.18 & $11-14$ & 8.60 & $9-11$ & 11.55 \\
\hline 9 & $24-34$ & 10.25 & $15-20$ & 10.53 & $12-18$ & 11.90 \\
\hline 10 & $35+$ & 10.11 & $21+$ & 9.34 & $19+$ & 9.61 \\
\hline
\end{tabular}

\footnotetext{
${ }^{a}$ Seasonal duck harvest for an individual hunter.

${ }^{b}$ Percent of hunters in the hunter group for each regulation period sample. Column totals may not equal $100 \%$ due to rounding.
}

seasonal harvest) for each harvest regulation period, whereas hunter group 1 represented the bottom-ranked $10 \%$ of hunters for each regulation period. The use of ranked hunter groups also allowed trends across hunters that varied in skill, experience, and persistence to be examined.

We examined seven measures of hunter behaviors; days harvesting ducks, daily harvest, hunter mobility (i.e., counties where hunters harvested ducks), mallard selectivity (\% mallard harvest), gender selectivity ( $\%$ female mallard harvest), daily female mallard harvest, and timing of harvest. We calculated individual hunter estimates for each measure of behavior, except for daily female mallard harvest (see below). We then averaged individual hunter estimates for each hunter group for each harvest regulation set. To calculate average days harvesting ducks, we quantified the total number of days an individual harvested at least one duck in a given season. To calculate average daily harvest, we first estimated individual hunter average daily bag, and then averaged those estimates across hunter groups and regulation sets. Daily bags that exceeded those legally allowed were removed from analysis as they may represent party bags or multiple daily bags. We examined the number of counties where harvest occurred seasonally for any individual to index hunter mobility. Hunter mobility was only examined to the county level, as this was the smallest geographical scale the PCS data contained. Additionally, because we first stratified the data by state to account for repetitive county numbers among states, we could not account for hunters who moved between states. Thus, a hunter who harvested ducks in multiple states would be considered a different hunter for each state they harvested ducks. Consequently, sample size for county data is larger than the reported seasonal bag sample size in the PCS. 
We examined mallard selectivity because mallard may be preferred by hunters (Gilmer, Hicks, Fleskes, \& Connelly, 1989). We calculated mallard selectivity and gender selectivity similarly. For mallard selectivity, we divided an individual hunter's seasonal harvest into mallard harvest and other duck harvest. To then calculate the percent mallard harvest for the hunter, we divided the individual's mallard harvest by their entire seasonal harvest. We calculated percent of total mallard harvest that was female to examine gender selectivity. Only mallards (and bags containing mallards) were considered for gender selectivity analyses because harvest regulations distinguish between mallard genders, whereas harvest regulations do not distinguish between genders for other species (Kruse, 2013; Kruse et al., 2002; U.S. Department of Interior, 2012). We calculated daily female mallard harvest, for bags that contained at least one mallard, as the average number of female mallards in individual hunter's daily bags for each hunter group and regulation set.

Finally, we calculated the timing of harvest as the mean seasonal day of harvest for any hunter group. We also examined mode and median seasonal day of harvest for all hunter groups and regulation sets, as well as the harvest distribution over time for hunter groups. We selected hunter groups 1, 5, and 10 from liberal seasons (2002-2011) to represent the range of hunter groups in a temporally relevant time period. Additional details on other hunter groups and periods can be found in Haugen (2013). Seasonal day of harvest was standardized among states, where it ran consecutively from the first day of the hunting season for a state to the last day of the hunting season for the same state for each year. Seasonal day of harvest did not account for splits or zones within a state, except in Texas when early season splits occurred at least 21 days earlier than other season days; these dates were removed from analyses.

We conducted an initial assessment of the dataset and removed records with apparent errors as needed (e.g., daily bags that exceeded those legally allowed and data with omitted hunter or county information). As such, variations in sample sizes exist. We calculated $95 \%$ confidence intervals $(95 \% \mathrm{CI})$ for estimates to determine if differences existed among hunter groups and harvest regulation sets. We considered non-overlapping confidence intervals to indicate strong evidence for differences between hunter groups or regulation sets (Johnson, 1999). Large sample sizes from the PCS may cause statically significant differences to exist though biological or managerial differences may not. We attempted to differentiate statistical differences from managerial differences when appropriate.

\section{Harvest Information Program Data and Analyses}

We obtained USFWS HIP diary data from the USFWS Branch of Harvest Surveys and edited the original HIP database to include only Central Flyway records on duck harvest during regular duck seasons (Kruse, 2013; Kruse et al., 2002). Hunters sampled for the HIP diary survey were randomly selected from hunters who registered with the HIP in the state they intended to hunt waterfowl (Raftovich \& Wilkins, 2013). Hunters must have indicated they hunted waterfowl the previous year to be eligible for selection in the HIP diary survey. We used the HIP diary data to compare relevant measures of behavior with those in the PCS; days hunted versus days harvesting ducks, daily harvest, and hunter mobility (number of counties where duck harvest occurred and counties hunted). We could not examine other measures of behaviors, such as those related to harvest compositions, as HIP diary data do not contain species-specific attributes. We only compared PCS and HIP diary data from 2002-2011 because the HIP diary data started in 1999. We did not include 1999-2001 regular duck seasons because allowable start and end dates for duck hunting season were different between 1999-2001 and 2002-2011. 
We again constructed ranked hunter groups using the same seasonal harvest breakdowns for 2002-2011 used for the PCS data (Table 1). We added an additional hunter group, hunter group 0 , to account for individuals who hunted but did not harvest ducks within the HIP data. We calculated HIP diary data estimates similar to the PCS estimates; however, the interpretation of these changed because the HIP diary data contains data related to no harvest.

For PCS analyses, we assumed that hunters turned in one wing from all ducks only they themselves harvested. We also assumed that hunters accurately recorded where and when a duck was harvested, and that wings were accurately identified to species and gender. For the HIP data, we assumed hunters accurately reported the number of ducks they themselves harvested, when and where the ducks were harvested, and their hunting effort.

\section{Results}

\section{Parts Collection Survey}

The PCS data provided 406,875 samples of individual ducks harvested, 165,147 from liberal seasons (2002-2011), 154,911 from moderate seasons (1975-1984), and 86,817 from restrictive seasons (1988-1993). The PCS also provided 37,317 seasonal bags from hunters, 10,458 from liberal seasons, 16,303 from moderate seasons, and 10,556 from restrictive seasons. There were 146,552 total daily bags from hunters sample by the PCS; 51,136 from liberal seasons, 53,414 from moderate season, and 42,002 from restrictive seasons.

Mean days harvesting ducks ( $n=37,208$ seasonal bags), daily harvest ( $n=35,107$ seasonal bags), and counties where duck harvest occurred ( $n=37,853$ seasonal bags) across all hunter groups and regulation periods were 4.2, 95\% CI [3.0, 5.5] days harvesting ducks, $2.4,95 \%$ CI [2.1, 2.7] ducks per day, and $1.3,95 \%$ CI [1.3, 1.4] counties, respectively. Mean percent mallard harvest ( $n=37,317$ seasonal bags), percent female mallard harvest $(n=$ 28,441 seasonal bags), and daily female mallard harvest $(n=86,061$ daily bags $)$ across all hunter groups and regulation periods were 46\%, 95\% CI [44, 48] mallards, $27 \%, 95 \%$ CI $[25,29]$ female mallards, and $0.4,95 \%$ CI $[0.4,0.5]$ female mallard harvested daily, respectively. Mean seasonal day of harvest $(n=405,574$ ducks harvested) across all hunter groups and regulation periods was $34.2,95 \% \mathrm{CI}[32.2,36.2]$ days after the start of season in a given state.

The mean number of days a hunter harvested ducks was similar for hunter groups 1-8 in restrictive and moderate seasons (Figure 1A). However, hunters harvested ducks on $0.4,95 \%$ CI $[0.0,0.9]$ more days when duck seasons were restrictive (season length: 39 days) relative to moderate duck seasons (season length: 60 days) due to differences in hunter groups 9 and 10 (Figure 1A). Hunters during liberal seasons (season length: 74 days) harvested ducks the most days: $1.0,95 \% \mathrm{CI}[0.5,1.4]$ more days, on average, than restrictive seasons and 1.4, 95\% CI [0.5, 2.2] more days, on average, than moderate seasons (Figure 1A). Hunters in all groups except group 1 harvested ducks on more days during liberal seasons.

Daily harvest trends increased from the hunter group 1 to hunter group 3 and then remained relatively constant or increased slightly across hunter groups 4-10 (Figure 1B). Daily harvest trends were relative to allowable daily bag limits. Samples for years with the greatest daily bag limits (i.e., liberal seasons, 2002-2011) had the greatest daily harvest across all ranked hunter groups (Figure 1B). However, the difference in daily bag limits from restrictive to moderate seasons ( 3 to 5 ducks) was greater than the difference in daily 

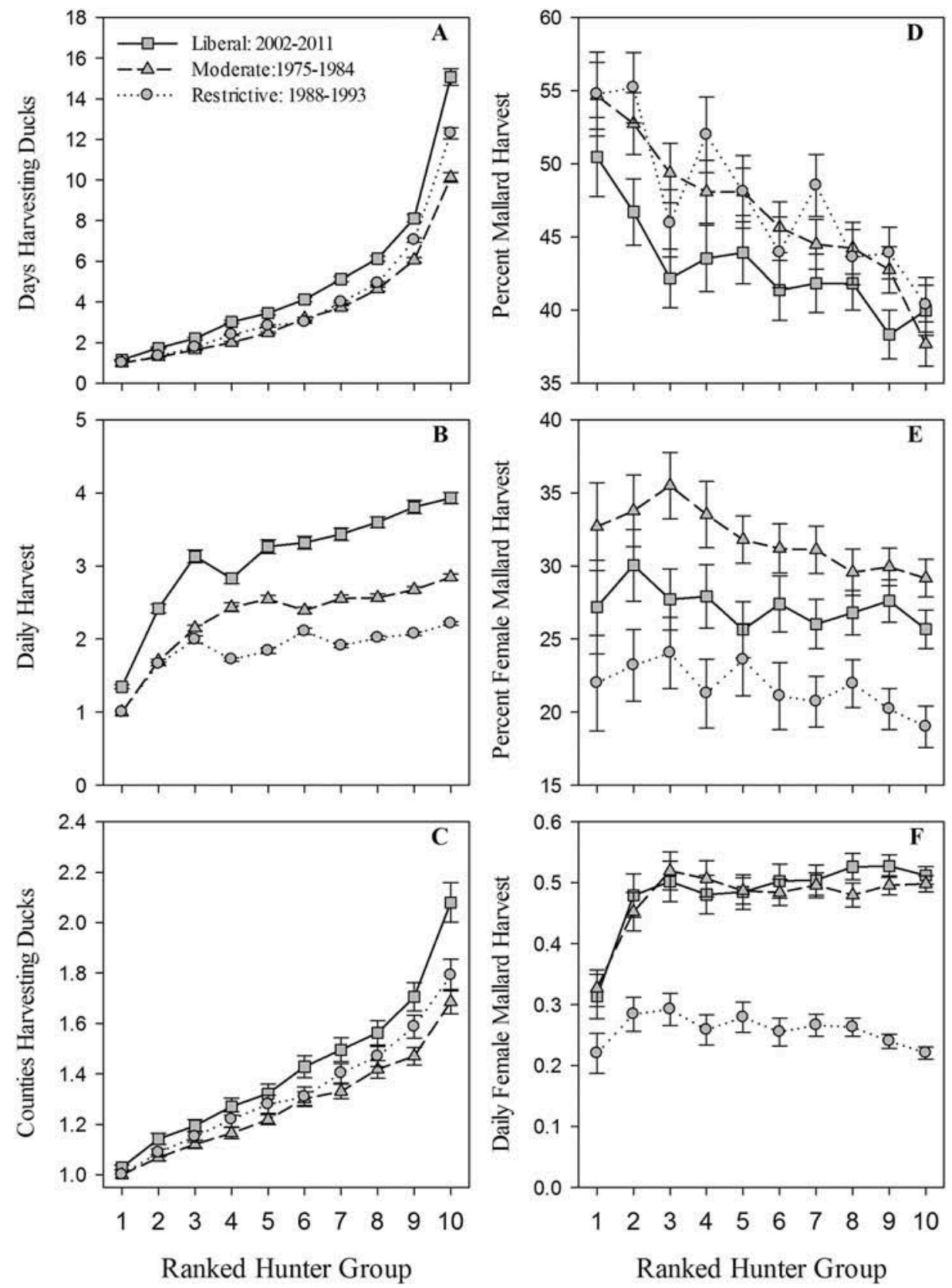

Figure 1. Mean estimates (95\% confidence intervals) for ranked hunter groups (10\% of each regulation period sample, stratified by seasonal harvest) for the measures of duck hunter behaviors of (A) days harvesting duck (\# of days when duck harvest occurred/hunter/season), (B) daily harvest (average daily bag/hunter/season), (C) hunter mobility (\# of counties where duck harvest occurred/hunter/season), (D) mallard selectivity (percent mallard harvest/hunter/season), (E) gender selectivity (percent female mallard harvest [mallards only] /hunter/season), and (F) daily female mallard harvest (for bags containing mallards only) from liberal (2002-2011), moderate (1975-1984), and restrictive (1988-1993) harvest regulations in the Central Flyway. Derived from U.S. Fish and Wildlife Service's Parts Collection Survey data. 
bag limits from moderate to liberal seasons (5 to 6 ducks). Whereas, the difference in daily harvest estimates between moderate and liberal seasons was greater than the difference between restrictive and moderate seasons.

Although hunter mobility (number of counties where hunters harvested ducks) increased as ranked hunter group increased, minor differences existed between hunter groups and regulation periods (Figure 1C). The average number of counties used by a hunter to harvest ducks across all regulation sets for hunter group 1 was 1.0, 95\% CI [1.0, 1.0] $($ Range $=1-2)$ counties and for hunter group 10 was $1.9,95 \%$ CI [1.6, 2.1] $($ Range $=$ $1-10)$ counties. The range of means for counties used to harvest ducks between all sampled hunters was relatively small, between 1.0 and 2.1 counties.

Mallard selectivity decreased as hunter group increased (Figure 1D). However, there was considerable overlap among hunter groups between regulation periods. Thus, regulations did not appear to affect mallard selectivity among hunters. Gender selectivity was constant across hunter groups, but shifted because of the regulation period (Figure 1E). Hunters during years with moderate seasons were the least selective (higher percent female mallard), followed by liberal and restrictive season hunters, respectively (Figure 1E).

Daily female mallard harvest increased initially from hunter group 1 to hunter group 2, however the number of female mallards harvested per day per hunter remained consistent for all remaining hunter groups (Figure 1F). Hunters harvested similar numbers of female mallards per day during liberal and moderate harvest regulations with a mean of $0.5,95 \%$ CI $[0.4,0.5]$ and $0.5,95 \%$ CI $[0.4,0.5]$ female mallards per day, respectively. Hunters harvested the fewest number of female mallards during restrictive harvest regulation period; $0.3,95 \%$ CI $[0.2,0.3]$ female mallards per day.

Mean day of harvest increased with hunter group. Mean day of harvest ranged from approximately day 37 (hunter group 6) to day 51 (hunter group 10) during liberal seasons. Moderate and restrictive seasons had similar estimates of mean day of harvest with an approximate range from day 26 (hunter group 3, restrictive seasons) and day 40 (hunter group 10, moderate seasons). Mode day of harvest was on the first day of hunting season for all hunter groups and regulations periods except hunter groups 7-10 during liberal seasons, where mode day of harvest was 8, 15, 29, and 29, respectively. Median day of harvest also increased with hunter group. Moderate and restrictive regulations again produced similar results as median day of harvest ranged from day 22 (hunter group 2, moderate seasons; hunter group 3, restrictive seasons) to day 35 (hunter group 10, moderate and restrictive seasons). Median day of harvest for liberal seasons ranged between day 30 (hunter group 5 and 6) and day 48 (hunter group 10).

Based on the distributions of harvest during 2002-2011, weekends are important for harvest, because spikes occurred on weekly intervals for all hunter groups examined (Figure 2). Lower ranked hunter groups harvest more than three times as many ducks during the first half of the season than they did during the second half of the hunting season (hunter group 1: 3.1 and hunter group 5: 3.5; Figure 2). In contrast, hunter group 10 harvested ducks more uniformly across a hunting season, only harvesting 1.7 times as many ducks during the first half of the season than during the last half (Figure 2).

\section{Harvest Information Program Diary Data Comparisons}

The HIP diary data provided 38,591 seasonal bags from sampled hunters for the days hunting ducks analysis, 26,685 for the daily harvest analysis, and 23,059 for the hunter mobility analysis in the Central Flyway from 2002-2011. Trends of days hunting ducks were similar 


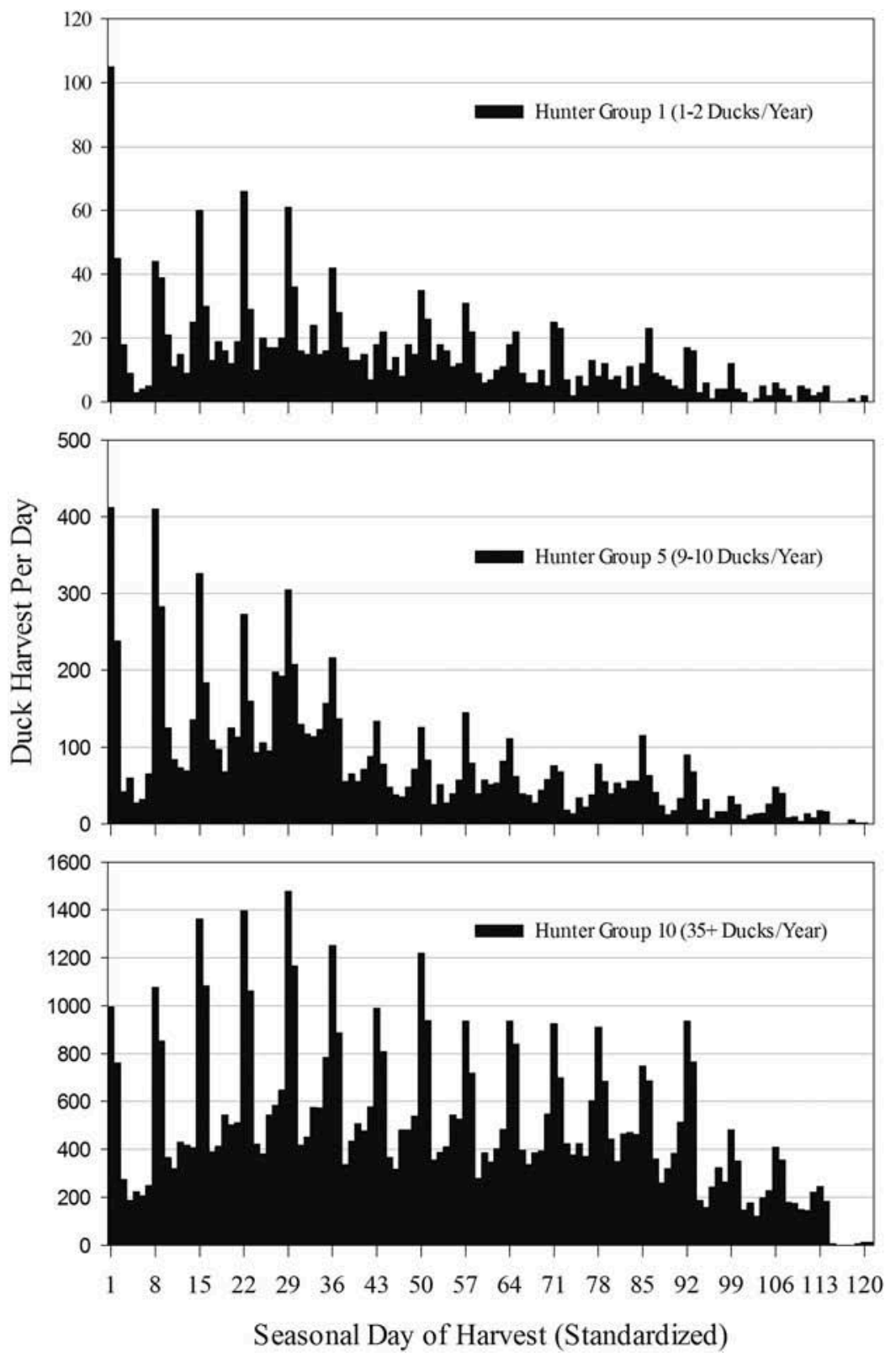

Figure 2. Temporal duck harvest distribution across hunting seasons (standardized hunting seasons for all states where the starting day of each states' season equaled 1) for Central Flyway hunters stratified into hunter groups 1 (1-2 ducks/hunter/year), 5 (9-10 ducks/hunter/year), and 10 (35+ ducks/hunter/year) from liberal seasons (2002-2011). Derived from U.S. Fish and Wildlife Service's Parts Collection Survey data.

between HIP and PCS results as hunter group increased. Hunters from the HIP diary sample hunted a mean of $6.8,95 \%$ CI [4.1, 9.5] days, and on average $2.2,95 \%$ CI $[1.9,2.5]$ more days than PCS estimates (Figure 3A). 

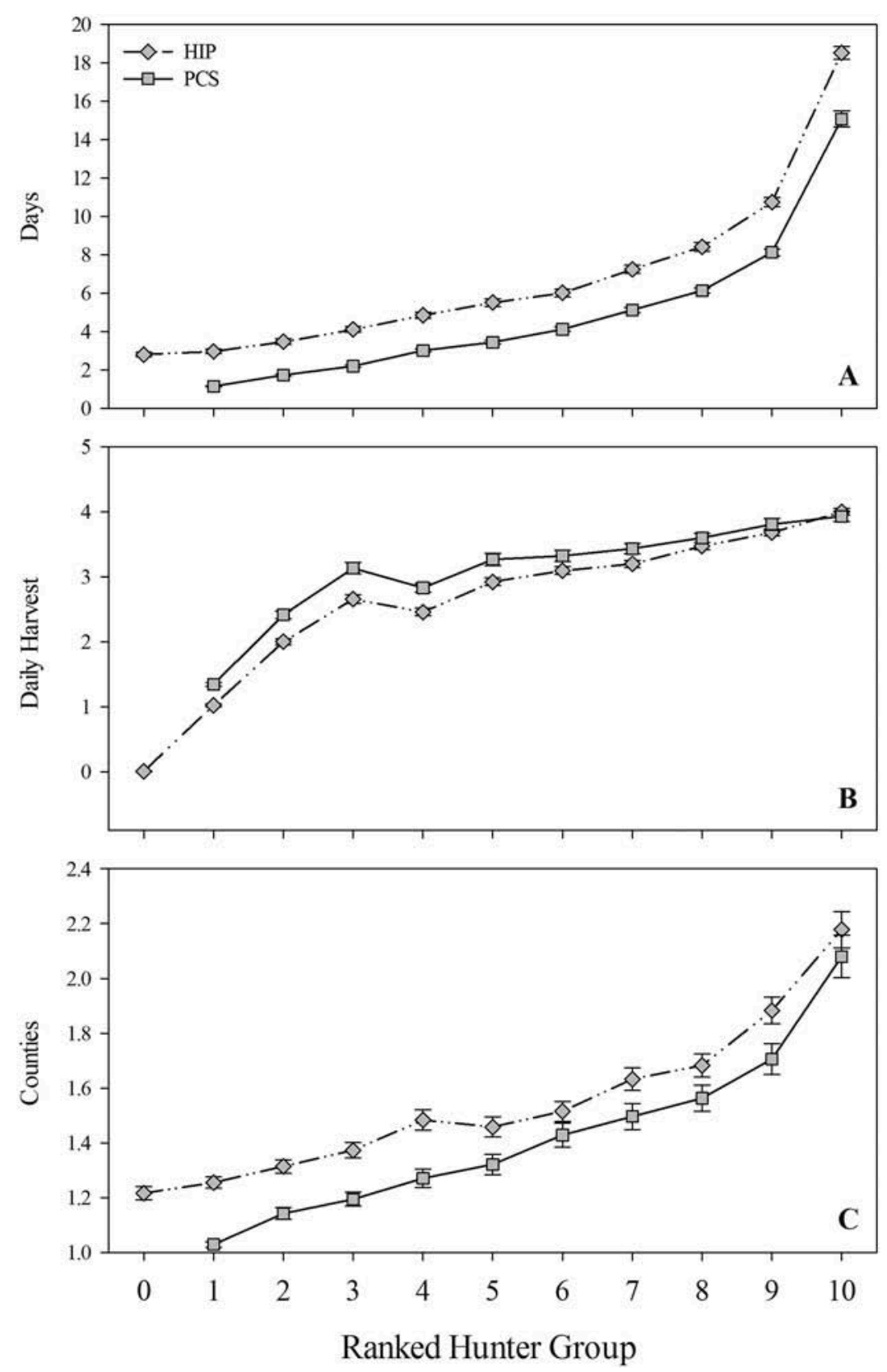

Figure 3. Mean estimates (95\% confidence intervals) from Harvest Information Program (HIP) and Parts Collection Survey (PCS) sampled hunters for ranked hunter groups (10\% for the regulation period sample, stratified by seasonal harvest; additional hunter group 0 added for non-harvesting HIP hunters) for the measures of duck hunter behaviors of (A) days hunted (HIP) and days harvesting ducks (PCS), (B) daily harvest (average daily bag), and (C) hunter mobility (\# of counties hunted [HIP] and \# of counties where harvest occurred [PCS]), Central Flyway 2002-2011. 
Mean daily bag and hunter mobility estimates exhibited similar trends in the PCS and HIP results as hunter group increased. Hunter group 1 in the HIP contained $\sim 50 \%$ daily bags of "no harvest," whereas hunter group 10 contained only $\sim 10 \%$ daily bags of "no harvest." Hunters in the HIP diary sample (contained daily bags of 0 ) harvested a mean of $2.6,95 \%$ CI $[1.9,3.3]$ ducks per day, and $0.3,95 \%$ CI $[0.2,0.4]$ fewer ducks per day than hunters from the PCS sample (did not contain daily bags of 0 ) (Figure 3B). Hunters from the HIP diary sample hunted a mean of $1.5,95 \%$ CI $[1.4,1.7]$ counties, and $0.2,95 \% \mathrm{CI}$ $[0.1,0.2]$ more counties than PCS sampled hunters (Figure 3C). For both variables, the HIP and PCS results contrasted the most for lower ranked hunter groups (Figure 3B-C). Means converged as hunter group increased (Figure 3B-C).

\section{Discussion}

Harvest regulations affected the number of days that a hunter harvested ducks. Longer seasons, however, did not always result in more days of harvest. Hunters during restrictive seasons (season length: 39 days) harvested ducks on a similar, or greater, number of days relative to moderate seasons (season length: 60 days). Although hunters have claimed season length may affect their participation (Ringelman, 1997), changes between season length and days harvesting ducks were not proportional. Hunter numbers were low during restrictive seasons and high during moderate seasons, with liberal seasons falling in between (Kruse 2013; Kruse et al., 2002). It is plausible that there were a higher proportion of "avid" hunters (i.e., hunters with greater persistence and dedication) during restrictive seasons relative to other frameworks because Barro and Manfredo (1996) found that as constraints to hunting increase, participation decreases, but high investment in the sport may maintain participation. The potential differences in relative persistence of hunters during regulation sets may have influenced the trend exhibited in days harvesting duck. As such, regulations may influence the composition of the hunting population, which may have implications for management and conservation.

Harvest distributions indicated hunters who harvested more ducks tended to hunt more uniformly across a season, and those who harvested few ducks tended to concentrate efforts at the beginning of the season. Moderate (1975-1984) and restrictive (1988-1993) seasons exhibited similar trends with regard to harvest distribution (Haugen, 2013). Thus, hunters who harvest few or many ducks may hunt in temporally distinct patterns. As such, different management strategies could be implemented at different times of the hunting season to target different hunters. For example, daily bag limits with no species restriction could be allowed during the beginning of the hunting season for hunters who harvest few ducks, which could potentially eliminate duck identification constraints (Enck et al., 1993).

Regulations did not appear to influence mallard selectivity among hunters. Mallard selectivity decreased as hunter group increased. Lower ranked hunter groups appeared to be more selective toward mallards; however, these trends may be influenced more by chance encounters with mallards rather than actual selectivity. Regardless, non-mallard species may be important to most hunters with regard to success because non-mallard species may comprise up to $60 \%$ of an individual's seasonal harvest. Our data support the conclusion of previous studies that suggested most hunters are opportunistic and may not actively select for any one particular species (Boyd, 1971; Hochbaum \& Walters, 1984; Mikula, Martz, \& Ryel, 1977; Nieman, Hochbaum, Casewell, \& Turner, 1986). Although mallard dominate hunter bags and may be an important species to hunters, managers should increase their consideration for the importance of non-mallard stocks to hunter success, and subsequently, hunter satisfaction. 
We anticipated that estimates of percent female mallard harvest and daily female mallard harvest would decrease across hunter groups regardless of harvest regulations because of expressions of selectivity made to managers (M. Vrtiska, NGPC, personal communication). This was not the case for the average duck hunter in the Central Flyway. Regulations were able to influence percent female mallard harvest and daily female mallard harvest, but these changes may be driven by allowable limits on female mallards in each regulation set, not hunter behaviors. Estimates for daily female mallard harvest were similar when the daily bag limit was two female mallards (moderate and liberal seasons); yet estimates were cut in half when the daily bag limit was one female mallard (restrictive seasons). A higher proportion of the mallard harvest was comprised of female mallards in moderate seasons relative to liberal seasons because regulations allowed for a higher proportion of female mallards in a daily bag. Specifically, regulations during moderate seasons allowed two female mallards in a four mallard limit, whereas liberal seasons allowed two female mallards in a five mallard limit. Monochromatic factors (i.e., when male and female mallards look alike due to molt) would be expected to reduce selectivity in harvest earlier and further north (Metz \& Ankney, 1991). Percent female mallard harvest, however, was unrelated to latitude (Haugen, 2013), and likely did not affect measures of gender selectivity.

Differences in hunter mobility among hunters and regulations were minimal. Most hunters only harvested ducks in one or two counties within a state during a season, which suggests a localized hunting effort. Hunters may be hunting in multiple locations within a county because the PCS is limited to county inferences. Additional studies may be warranted to address hunter mobility on a finer scale.

Mean daily bag estimates were greater and estimated numbers of counties where harvest occurred were less in the PCS relative to the HIP simply because the PCS does not contain data related to zero harvest. For daily bag and hunter mobility estimates, however, the differences between the datasets were minimal. Unsuccessful days afield remained relatively constant across hunter groups in the HIP sample. That is, regardless of how many ducks a hunter harvests seasonally, they all failed to harvest ducks on approximately two hunting trips. Managers can use this result to explain to their constituents how hunting effort affects harvest, which could be important as harvest and expectations can still be a large component of hunter satisfaction (Applegate, 1989; Brunke \& Hunt, 2007; Stankey, Lucas, \& Ream, 1973).

Hunters in lower-ranked hunter groups often showed minimal differences in harvest metrics (Figure 1) among the regulation periods, and metrics of the lower-ranked groups were especially similar during periods with restrictive and moderate regulations. We note that hunter groups 1-4 had identical seasonal bag sizes during periods of restrictive and moderate regulations (Table 1). And, hunter group 1 from liberal seasons, and hunter groups 1 and 2 from moderate and restrictive seasons were comprised of hunters who harvested 2 or fewer ducks seasonally. Therefore, we would expect to see few differences in metrics among periods, as low-ranked hunters (by definition) have small seasonal harvests and would be expected to behave in similar fashion regardless of regulations. In contrast, higher-ranked hunters (e.g., hunter groups 9 and 10) responded to liberal seasons with larger seasonal bags and were constrained by restrictive seasons (Table 1). Thus, these groups should be expected to show different behaviors among the three time periods in our study.

The inference from our study is from participants in the PCS and HIP diary surveys, who are selected from successful hunters. More successful hunters were selected at a higher rate (Raftovich \& Wilkins, 2013). As such, the PCS sample is not a random sample of waterfowl hunters. Even so, the patterns derived from among-period comparisons of the 
hunters in the PCS sample provide useful information to assist waterfowl managers in decision-making.

Changes in regulations can affect measures of hunter behaviors. Our data should help managers anticipate how hunters will respond to changes in regulations, and subsequently how harvest may be affected. Regardless of regulations, however, hunters who harvest many ducks seasonally (i.e., hunter groups 9 and 10) hunt more days, are slightly more mobile, and have a higher average daily bag. Hunters who harvest very few ducks seasonally (i.e., hunter groups 1 and 2) tend to hunt fewer days and counties. Consequently, this study may reveal two typologies of hunters, with a possible gradient of hunters in between. Although typologies of hunters have been described for experience preferences (Schroeder et al., 2006), our study describes typologies based on harvest metrics of hunters. A typology of hunters based on harvest metrics may inform the link between human dimensions and harvest management, which could prove beneficial in determining the role harvest management plays in hunter recruitment and retention.

\section{Acknowledgments}

Matthew T. Haugen is now at Ducks Unlimited, Inc.

We thank the USFWS for providing us with the PCS data, specifically K. Wilkins and R. Raftovich. We are grateful to all the waterfowl hunters who participated in the PCS and HIP diary survey. We thank J. Lawrence, J. Vaske, and three anonymous reviewers for helpful comments on earlier drafts of this article.

\section{Funding}

Funding was provided by the Nebraska Game \& Parks Commission and was supported by Hatch Act funds through the University of Nebraska Agricultural Research Division, Lincoln, Nebraska. Any use of trade, firm, or product names is for descriptive purposes only and does not imply endorsement by the U.S. Government. The Nebraska Cooperative Fish and Wildlife Research Unit is jointly supported by a cooperative agreement among the U.S. Geological Survey, the Nebraska Game and Parks Commission, the University of Nebraska, the U.S. Fish and Wildlife Service, and the Wildlife Management Institute.

\section{References}

Applegate, J. E. (1989). Patterns of early desertion among New Jersey hunters. Wildlife Society Bulletin, 17, 476-481.

Atwood, E. L. (1956). Validity of mail survey data on bagged waterfowl. Journal of Wildlife Management, 20, 1-16.

Baldassarre, G. A., \& Bolen, E. G. (2006). Waterfowl ecology and management (2nd ed.). Malabar, FL: Krieger.

Barro, S. C., \& Manfredo, M. J. (1996). Constraints, psychological investment, and hunting participation: Development and testing of a model. Human Dimensions of Wildlife, 42-61.

Boyd, H. (1971). Observations on duck hunting in eastern Canada in 1968 and 1969 (Occasional Papers 12). Ottawa, Canada: Canadian Wildlife Service.

Brunke, K. D., \& Hunt, K. M. (2007). Comparison of two approaches for the measurement of waterfowl hunter satisfaction. Human Dimensions of Wildlife, 12, 443-457.

Enck, J. W., Swift, B. L., \& Decker, D. J. (1993). Reasons for decline in duck hunting: Insights from New York. Wildlife Society Bulletin, 21, 10-21. 
Gilmer, D. S., Hicks, J. M., Fleskes, J. P., \& Connelly, D. P. (1989). Duck harvest on public hunting areas in California. California Fish and Game, 75, 155-168.

Haugen, M. T. (2013). The influence of regulations on duck hunters and harvest (Master's thesis). University of Nebraska-Lincoln, Lincoln, NE.

Hochbaum, G. S., \& Walters, C. J. (1984). Components of hunting mortality in ducks: A management analysis (Occasional Papers 52). Ottawa, Canada: Canadian Wildlife Service.

Johnson, D. H. (1999). The insignificance of statistical significance testing. Journal of Wildlife Management, 63, 763-772.

Johnson, F. A., \& Case, D. J. (2000). Adaptive regulations of waterfowl harvests: Lessons learned and prospects for the future. Transaction of the North American Wildlife and Natural Resources Conference, 65, 94-108.

Johnson, K. N., Johnson, R. L., Edwards, D. K., \& Wheaton, C. A. (1993). Public participation in wildlife management: Opinions from public meetings and random surveys. Wildlife Society Bulletin, 21, 218-225.

Kruse, K. L. (Compiler). (2013). Central Flyway harvest and population survey data book. Denver, CO: U.S. Fish and Wildlife Service.

Kruse, K. L., Sharp, D. E., Ladd, W. N., Moser, T. J., \& Bublitz, E. A. (Compilers). (2002). Central Flyway waterfowl hunting and harvest survey information, 1961-2001. Denver, CO: U.S. Fish and Wildlife Service.

Martin, E. M., \& Carney, S. M. (1977). Population ecology of the mallard: IV. A review of duck hunting regulations, activity, and success, with special reference to the mallard (Resources Publication 130). Washington, DC: U.S. Department of Interior, Fish and Wildlife Service.

Metz, K. J., \& Ankney, C. D. (1991). Are brightly colored male ducks selectively shot by hunters? Canadian Journal of Zoology, 69, 279-282.

Mikula, E. J., Martz, G. F., \& Ryel, L. A. (1977). A comparison of lead and steel shot for waterfowl hunting. Wildlife Society Bulletin, 5, 3-8.

Miller, C. A., \& Vaske, J. J. (2003). Individual and situational influences on declining hunter effort in Illinois. Human Dimensions of Wildlife, 8, 263-276.

National Flyway Council and Wildlife Management Institute. (2006). National duck hunter survey, 2005 national report. Minnewaska, IN: D. J. Case and Associates.

Nichols, J. D., Runge, M. C., Johnson, F. A., \& Williams, B. K. (2007). Adaptive harvest management of North American waterfowl populations: A brief history and future prospects. Journal of Ornithology, 148, S343-S349.

Nieman, D. J., \& Caswell, F. D. (1989). Field observations of hunters: The spy blind approach. In K. H. Beattie (Ed.). Proceedings from the Sixth International Waterfowl Symposium (pp. 160-165). Memphis, TN: Ducks Unlimited.

Nieman, D. J., Hochbaum, G. S., Caswell, F. D., \& Turner, B. C. (1986). Monitoring hunter performance in prairie Canada. Transactions of the North American Wildlife and Natural Resources Conference, 52, 233-245.

Pendleton, G. W. (1992). Nonresponse patterns in the federal waterfowl hunter questionnaire survey. Journal of Wildlife Management, 56, 344-348.

Peterle, T. J. (1967). Characteristics of some Ohio hunters. Journal of Wildlife Management, 31, 375-389.

Pierce, C. L., Ringelman, J. K., \& Szymczak, M. R. (1996). An investigation of factors affecting waterfowl hunting participation in Colorado. Human Dimensions of Wildlife, 1, 80-81.

Raftovich, R. V., \& Wilkins K. A. (2013). Migratory bird hunting activity and harvest during the 2011-12 and 2012-13 hunting seasons. Laurel, MD: U.S. Department of Interior, Fish and Wildlife Service.

Ringelman, J. K. (1997). Effects of regulations and duck abundance on duck hunter participation and satisfaction. Transactions of the North American Wildlife and Natural Resources Conference, 62, $361-376$.

Schroeder, S. A., Fulton, D. C., \& Lawrence, J. S. (2006). Managing for preferred hunting experiences: A typology of Minnesota waterfowl hunters. Wildlife Society Bulletin, 34, 380-387. 
Stankey, G. H., Lucas, R. C., \& Ream, R. R. (1973). Relationship between hunting success and satisfaction. Transactions of the North American Wildlife and Natural Resources Conference, 38 , 235-242.

Stedman, R., Diefenbach, D. R., Swope, C. B., Finley, J. C., Luloff, A. E., Zinn, H. C., . . Wang, G. A. (2004). Integrating wildlife and human-dimensions research methods to study hunters. Journal of Wildlife Management, 68, 762-773.

U.S. Department of Interior. (2012). Migratory bird hunting, late seasons and bag and possession limits of certain migratory game birds (77 Federal Register 184). Washington, DC: U.S. Department of Interior, Fish and Wildlife Service.

U.S. Fish and Wildlife Service. (2013). Adaptive harvest management: 2013 hunting season. Washington, DC: U.S. Department of Interior, Fish and Wildlife Service.

Van Deelen, T. R., \& Etter, D. R. (2003). Effort and the functional response of deer hunters. Human Dimensions of Wildlife, 8, 97-109.

Vrtiska, M. P., Gammonley, J. H., Naylor, L. W., \& Raedeke, A. H. (2013). Economic and conservation ramifications from the decline of waterfowl hunters. Wildlife Society Bulletin, 37, $380-388$. 